\title{
Wood powders of different botanical origin as an alternative to barrel aging for red wine
}

\author{
Maria Tiziana Lisanti ${ }^{1}$ (1) $\cdot$ Rosa Capuano $^{1} \cdot$ Luigi Moio $^{1} \cdot$ Angelita Gambuti $^{1}$
}

Received: 2 March 2021 / Revised: 26 May 2021 / Accepted: 29 May 2021 / Published online: 15 June 2021

(c) The Author(s) 2021

\begin{abstract}
Wood powders are produced in large quantity as by-product of barrel, staves and chips industry. Differently from larger particles (chips), the use of wood powders in winemaking is not admitted (Regulation (CE) n. 934/2019); however, it could represent a cheap and sustainable alternative for the accelerated aging of red wine. To evaluate their potential use in winemaking, a comparative study on the use of wood powders from oak, chestnut and acacia wood for the accelerated aging of red wine ( $c v$. Aglianico) was conducted. This alternative aging was compared to the aging in wood barrels from the same botanical species. The wine aged in contact with powders underwent a quicker evolution of polyphenolic fraction. After 15 days of contact, the loss of total anthocyanins was higher than that observed after 6 months of aging in barrels (from 4 to $14 \%$ with respect to the corresponding kind of barrel). The amount of polymeric pigments tannins-anthocyanins-tannins in wines aged in contact with powders was higher respect to the wines aged in barrels (from 7 to $21 \%$ with respect to the corresponding kind of barrel), while the greatest loss of total tannins was detected in the oak barrels (28\% less with respect to the control). There were several differences in wine phenolic acids due to wood botanical origin, with the clearest differences being between oak and the alternative wood species (chestnut and acacia). Also, there was a significant botanical effect on sensory profiles. Indeed, both among barrels and among powders, oak wood was the one that gave the strongest wood odor character. However, all the treatments with wood powders (oak, acacia and chestnut) preserved the fruity character of wine, conferring in the meanwhile non-dominant woody notes.
\end{abstract}

Keywords Oak $\cdot$ Acacia $\cdot$ Chestnut $\cdot$ Sensory analysis $\cdot$ Polyphenols $\cdot$ Wood powders

\section{Introduction}

The aging in oak barrels is a common practice in the production of high-quality red wines. The improvement of sensory quality of wines stored in barrel is mainly due to two phenomena: the micro-oxygenation of wine, due to the small amounts of air that slowly pass through the pores of the staves, and the release of sensory active compounds from wood to wine [1]. Micro-oxygenation causes several oxidation reactions involving wine phenolics, which results first in the production of acetaldehyde from ethanol and various aldehydes from other organic wine components [2]. Aldehydes can, in turn, react with anthocyanins to form stable

Maria Tiziana Lisanti

mariatiziana.lisanti@unina.it

1 Dipartimento di Agraria-Sezione di Scienze della Vigna e del Vino, Università degli Studi di Napoli Federico II, viale Italia, 83100 Avellino, Italy reddish or violet polymeric pigments [3] and/or they can react with monomeric and low-molecular-weight condensed flavanols (low-molecular-weight tannins) determining their polymerization [4]. These processes determine the stabilization of wine color and, in some cases, a decrease of tannin astringency $[5,6]$. Among the compounds released from wood to wine during aging, ellagitannins are quantitatively the most important ones [7]. These complex molecules are essentially astringent [8], but, once in wine, they participate in condensation, hydrolysis, and oxidation reactions [9] that change their capability to react with saliva and elicit astringency [10] and that determine their contribution to color stabilization [11]. Other phenolic compounds at low-molecular-weight change their concentration when wine is aged in contact with wood, as caffeic, $p$-coumaric, and ferulic acids, and they were found to allow a discrimination among the botanical origins of wood and the sizes of wood pieces in contact with wine $[12,13]$. 
Oak wood aging also contributes to wine aroma, by releasing odor active compounds, such as oak lactones (cis- and trans- $\beta$-methyl- $\gamma$-octalactone) and wood thermal degradation derivatives (phenolic aldehydes and ketones, volatile phenols, lactones, furanic and pyranic compounds), that enrich wine odor profile with toasty, coconut, vanilla, and spicy notes [1].

The chemical nature and levels of the released compounds (ellagitannins and volatiles) as well as the oxygen permeability and adsorption phenomena involving wine phenolics and volatiles can vary greatly depending on the botanical and geographical origin of wood, the ratio of wood surface area to wine volume, the humidity and temperature of winery, the alcohol level, the wine composition, the reuse of barrel, as well as on the processing that undergoes in cooperage, seasoning and toasting [14-19].

Barrel aging is undoubtedly the most used practice to improve sensory quality of red wine by contact with wood, and oak species (mainly Quercus petraea, Quercus robur, and Quercus alba) are traditionally used in barrel making [1].

However, barrel aging is an expensive process due to the cost of barrels, the space needed in winery and the long storage time required. Additionally, the prevention of the contamination by undesirable microorganism, such as Brettanomyces causing phenolic off-flavor, is time- and moneyconsuming [20], and not always effective, with the consequent need for curative treatments of tainted wines [21].

A cheaper and faster alternative to enrich wine with wood compounds consists in putting wine in contact with toasted small pieces of wood, called chips. Wood chips present a greater surface area in contact with wine than barrels, thus allowing a quicker release of volatiles and phenolics, affected by the size of wood pieces [22, 23]. A recent study [13] showed that, when two types of seasoning and three types of toasting of chips and staves made from the wood of Quercus pyrenaica Willd. were compared, the size of the alternative product was the factor that determines the phenolic composition of the wines over the entire aging process, regardless of the seasoning or toasting method carried out on wood. Also the ratio "amount of chips/volume of wine", the contact time, the dimensions and forms of wood pieces, and the toasting level drive the outcome of the treatment [1, 24]. On the base of European regulation, wood chips used in winemaking must be retained at least for $95 \%$ in weight by a filter with $2 \mathrm{~mm}$ pore size ( 9 mesh) and the wood must come exclusively from the Quercus genus (Regulation (CE) n. 934/2019). However, wood powders smaller in size represent the main by-product of barrel, staves, and chips industry. Their use may represent a potential advantage for cooperages, by the valorization of a residue of production, and it could contribute to increase the sustainability of winemaking process. Moreover, the use of wood powders (i.e., wood pieces with mean particle diameter $<2 \mathrm{~mm}$ ) could allow to further reduce the time for treatments, which represents an important advantage in the winemaking process.

Another important issue is the extensive use of oak wood for cooperage (both barrels and chips) which presents environmental constraints, due to the intensive harvesting of oak trees in forests [25]. Therefore, the use of wood from different botanical species may contribute to the environmental sustainability of wood production chain. In recent years, wood from botanical species other than oak, such as chestnut, cherry, mulberry, acacia, was studied as material for barrels [23, 26-31]. The use of these alternative woods may offer potential advantages in winemaking, such as to adapt the wine aging to the intrinsic characteristics of wine and to differentiate wine sensory profiles, besides allowing to reduce the environmental impact of the massive use of oak wood [23, 26-31]. Analogously to what studied for barrel aging, also in the case of contact with wood chips, the use of wood from botanical species other than oak may contribute differently to the sensory profile of wine [25, 32].

In the present study, both these aspects (the use of botanical species other than oak and the valorization of wood powders from barrel and chips industry) were considered. Wood powders of different botanical origins (oak, chestnut and acacia) were tested for the accelerated aging of red wine ( $c v$. Aglianico), in comparison to the aging in wood barrels from the same botanical species. The comparison was made in terms of phenolic composition and sensory profile. To the best of our knowledge, it is totally new in what concerns the valorization of wood powders from different botanical species for the aging of red wine.

\section{Materials and methods}

\section{Wine}

Grapes of Vitis vinifera $c v$. Aglianico were obtained from vineyards located in the area surrounding the city of Benevento (Campania, Italy). Grapes were destemmed and crushed; the must was treated with Potassium metabisulfite (60 mg/kg of grapes). Fermentation took place at $26{ }^{\circ} \mathrm{C}$ with indigenous yeasts and the cap was immersed twice a day by pumping over. Alcoholic fermentation took 12 days. Maceration of the pomace lasted 15 days. The free-run red wine was separated from the pressed one and, after malolactic fermentation, conducted in stainless-steel tank, it was racked and sulfited $\left(30 \mathrm{mg} / \mathrm{L} \mathrm{SO}_{2}\right)$ and used to perform the wood aging experiments 6 months after the winemaking. Base parameters of Aglianico wine were: residual sugars $=1.8 \pm 0.09 \mathrm{~g} / \mathrm{l}$, ethanol content $=13.5 \pm 0.08 \% \mathrm{v} / \mathrm{v}$, volatile acidity $=0.45 \pm 0.04 \mathrm{~g} / \mathrm{l}$, total acidity $=6.2 \pm 0.3 \mathrm{~g} / \mathrm{l}$, pH $3.34 \pm 0.01$, and total dry extract $30.5 \pm 0.4 \mathrm{~g} / \mathrm{l}$. Titrable 
acidity, $\mathrm{pH}$ and volatile acidity were monitored during aging and did not show significant differences in all the trials. The variations of alcohol degree were less than $0.5 \% \mathrm{v} / \mathrm{v}$ in all the trials. Free $\mathrm{SO}_{2}$ was measured at the beginning and after the aging experiment with the following results: at the beginning of the experiment free $\mathrm{SO}_{2}$ was $20 \pm 1.8 \mathrm{mg} / \mathrm{L}$, at the end of the experiment free $\mathrm{SO}_{2}$ was $<10 \mathrm{mg} / \mathrm{L}$ in all barrel and powder aged wines, while in control wine it was $15 \pm 1.2 \mathrm{mg} / \mathrm{L}$.

\section{Experimental design}

The Aglianico wine was divided into five aliquots. Three aliquots were stored for 6 months in the traditional wood storage containers: (a) $225 \mathrm{~L}$ new barrels of chestnut (Castanea sativa), medium-toasted (Chest-B) (Bottai Cione srl, Caposele, AV, Italy); (b) $225 \mathrm{~L}$ new barrels of acacia (Robinia pseudoacacia), medium-toasted (Aca-B) (Bottai Cione srl, Caposele, AV, Italy); (c) $225 \mathrm{~L}$ new barrels of French oak Allier (Quercus petraea), medium-toasted (Oak-B) (Tonnellerie Remond, Ladoix Serrigny, France). An additional aliquot of wine $(500 \mathrm{~L})$ was stored in a stainless-steel tank. Fifteen days before the racking of barrel aged wines, aliquots of $50 \mathrm{~L}$ of the wine stored in the stainless-steel tank were put in demijohns of $54 \mathrm{~L}$, each added with a different wood powder $(100 \mathrm{~g} / \mathrm{hL})$ by means of infusion bags. The wood powders used were the following: (a) chestnut powder (Chest-P), (b) acacia powder (Aca-P) and (c) oak powder (Oak-P). All the powders had a size of $1.5 \times 1.5 \times 1 \mathrm{~mm}$ and were medium-toasted $\left(180^{\circ} \mathrm{C}, 20 \mathrm{~min}\right)$. The same companies that purchased the barriques, purchased powders of the correspondent woods. Wine was taken in contact with the powders for 15 days at a temperature of $12{ }^{\circ} \mathrm{C}$, and each demijohn was shaken one time per day. The amount of powders and the contact time used in this study were selected by preliminary sensory trials, in order to avoid an excessive impact of the wood character in wines. All the wood contact modalities (barrels and wood powders) were performed in duplicate. After racking, the experimental wines were bottled and analyzed after 1 month. Also, the aliquot stored in the stainless-steel tank was bottled and considered as a control.

\section{Spectrophotometric measurements}

Total polyphenols (Folin-Ciocalteau Index) were measured according to the Official European Methods (1990). Color intensity, hue, Abs $420 \mathrm{~nm}$, Abs $520 \mathrm{~nm}$, Abs $620 \mathrm{~nm}$, dAL $\%$ (percentage of free anthocyanins), dAT \% (percentage of anthocyanins combined with tannins and bleached by $\mathrm{SO}_{2}$ ) and $\mathrm{dTaT} \%$ (percentage of anthocyanins combined with tannins and unaffected by $\mathrm{SO}_{2}$ ) were evaluated according to Glories method [33]. Total anthocyanins were determined by a spectrophotometric method based on $\mathrm{SO}_{2}$ bleaching [34]. Tannins were determined by acid hydrolysis in an alcoholic medium for the analysis of condensed tannins according to Ribéreau-Gayon and Stonestreet [35]. Vanillin reactive flavans were measured by adding a solution of vanillin to wine previously diluted with methanol, and then, after adding hydrochloric acid, the absorbance was determined at $500 \mathrm{~nm}$ as described by Di Stefano and co-workers [36] For each replicate of the treatments, three bottles were mixed and analyzed in duplicate $(n=4)$.

\section{HPLC analysis}

\section{Equipment}

Separation and quantification of polyphenols were carried out by HPLC. The HPLC used was a Shimadzu apparatus (Shimadzu Italy, Milan) LC10 ADVP, consisting of an SCL-10AVP system controller, two LC-10ADVP pumps, an SPD-M 10 AVP detector, and an injection system full Rheodyne model 7725 (Rheodyne, Cotati, CA) equipped with a $50 \mu \mathrm{L}$ loop.

\section{Phenolic acids}

The wine samples were analyzed following the method previously described by Fernández and co-workers [37], with some modifications. The column used for this separation was a Nova-Pak $\mathrm{C}_{18}$ column $(3.9 \times 150 \mathrm{~mm}, 4 \mu \mathrm{m}$ particles diameter) equipped with a Nova-Pak Sentry $\mathrm{C}_{18}$ guard column $(3.9 \times 20 \mathrm{~mm}, 4 \mu \mathrm{m})$ (Waters Corporation). Wine samples were concentrated to $25 \%$ of their initial volume and then they were extracted with diethyl ether and ethyl acetate. The organic fractions were combined and evaporated to dryness. The obtained residues were redissolved in $\mathrm{MeOH}-\mathrm{H} 2 \mathrm{O}(1: 1)$ and then $50 \mu \mathrm{L}$ of extracts or calibration standards were injected into the HPLC.

The mobile phase consisted of $2 \%(\mathrm{v} / \mathrm{v})$ acetic acid in water (eluent $\mathrm{A}$ ) and $0.5 \%$ acetic acid in water and acetonitrile $(50: 50, \mathrm{v} / \mathrm{v}$; eluent $\mathrm{B})$. The elution program was as follows: $0 \mathrm{~min}, 95 \% \mathrm{~A}, 5 \% \mathrm{~B}$ at a flow rate of $1 \mathrm{~mL} / \mathrm{min}$; $5 \mathrm{~min}, 90 \% \mathrm{~A}, 10 \% \mathrm{~B}$ at a flow rate of $1 \mathrm{~mL} / \mathrm{min} ; 6.5 \mathrm{~min}$, $85 \% \mathrm{~A}, 15 \% \mathrm{~B}$ at $1 \mathrm{~mL} / \mathrm{min} ; 12 \mathrm{~min}, 75 \% \mathrm{~A}, 25 \% \mathrm{~B}$ at a flow rate of $1 \mathrm{~mL} / \mathrm{min} ; 25 \mathrm{~min}, 45 \% \mathrm{~A}, 55 \% \mathrm{~B}$ at a flow rate of $1 \mathrm{~mL} / \mathrm{min} ; 25.5 \mathrm{~min}, 100 \% \mathrm{~B} ; 28.1 \mathrm{~min}, 95 \% \mathrm{~A}$, $5 \% \mathrm{~B}$ until the end of analysis at $30 \mathrm{~min}$. Detection was performed by monitoring the absorbance signals at $280 \mathrm{~nm}$ and $306 \mathrm{~nm}$. The calibration curves were made up by their respective standards covering the range of linearity and were characterized by a correlation coefficient $\left(r^{2}\right)>0.998$. For each replicate of the treatments, three bottles were mixed and analyzed in duplicate $(n=4)$. 


\section{Sensory analysis}

Odor profiles of the experimental wines were obtained by quantitative descriptive sensory analysis. The panel was composed of 8 judges ( 4 males and 4 females, 22-45 years of age) recruited from the staff and the students of the Department of Food Science of the University of Naples Federico II, selected on the basis of their sensory abilities and specifically trained in recognizing and rating taste attributes, odor attributes and astringency of wood aged red wines. The odor attributes to evaluate were determined by consensus after the panel had discussed to reduce the number of descriptors, in two dedicated sessions before the measure sessions. All the sensory analyses were conducted in individual sensory booths. The wine samples $(30 \mathrm{~mL})$ were served in black tulip-shaped wine glasses, coded with random three-digit codes, at room temperature $\left(18-20^{\circ} \mathrm{C}\right)$. The order of presentation of the samples was randomized among the judges to minimize any possible order and carryover effects. The intensities of sensory descriptors were rated using a 9 -point scale $(0=$ not detected, $1=$ weak, $2=$ medium, $3=$ strong, $4=$ very strong, half values being allowed). For each descriptor, the parameter known as modified frequency (MF) was calculated as proposed by Dravnieks [38]: MF $(\%)=[\mathrm{F}(\%) \times \mathrm{I}(\%)]^{1 / 2}$, where F $(\%)$ is the frequency of citation expressed as a percentage of the maximum frequency of citation (i.e., the total number of judges) and I (\%) is the mean intensity expressed as a percentage of the maximum intensity (i.e., the value of four). The two replicates of each treatment were mixed (two bottles for each replicate) and analyzed in duplicate.

\section{Statistical analysis}

Quantitative data relative to standard chemical analysis, spectrophotometric measurement, phenolic acids, anthocyanins, and sensory profiles were submitted to oneway ANOVA; Tukey's test was used to discriminate among the means of the variables (for both, $p<0.05$ was considered significant). Multifactorial ANOVA was used to evaluate the relationships among factors for chemical and spectrophotometric data. Differences of $p<0.05$ were considered significant. Chemical and sensory data were also submitted to multivariate analysis (Principal Component Analysis). All the statistical analyses were performed using XLSTAT-Pro 7.5.3 (Addinsoft).

\section{Results and discussion}

\section{Effect on chromatic characteristics and phenolic compounds}

Wood aging determines a wide group of reactions and a series of changes involving wine phenolics that can, or not, stabilize red wine color and decrease wine astringency. These reactions are essentially due to three processes: moderate oxidation [39], reactions with reactive compounds extracted from wood such as ellagitannins or phenolic aldehydes $[11,40]$ and adsorption of wine native phenolics on wood surface [12].

First parameters changing during wine aging are chromatic characteristics owing to the great reactivity of grape native anthocyanins, and several studies showed that color intensity increased as a result of wood chips addition after fermentation [41, 42]. In our study, except for Aca-B, for all wines, no significant differences in color intensity were detected (Table 1). In contrast, a different contribution of polymerized pigments to total wine color was observed (Table 1): a loss of native anthocyanins (dAl) and anthocyanin-tannin pigments (dAT) (with exception of Aca-B and Chest-B samples, respectively), was observed after contact

Table 1 Effect of wood aging mode on chromatic characteristics and anthocyanin distribution of the experimental wines (mean \pm standard deviation)

\begin{tabular}{lllllllll}
\hline Samples & Abs $_{420 \mathrm{~nm}^{\ddagger}}$ & Abs $_{520 \mathrm{~nm}}{ }^{\ddagger}$ & Abs $_{620 \mathrm{~nm}}^{\ddagger}$ & Color intensity & Hue $^{\ddagger}$ & dTAT\% $^{\ddagger}$ & $\mathrm{dAl}^{\ddagger}$ & $\mathrm{dAT}^{\ddagger}$ \\
\hline Control & $6.8 \pm 0.2 \mathrm{ab}$ & $12.6 \pm 0.3 \mathrm{a}$ & $2.5 \pm 0.1 \mathrm{bc}$ & $21.9 \pm 0.4 \mathrm{~b}$ & $0.54 \pm 0.01 \mathrm{a}$ & $17.5 \pm 2.2 \mathrm{a}$ & $15.6 \pm 1.2 \mathrm{~b}$ & $67.4 \pm 2.0 \mathrm{c}$ \\
Chest-B & $7.1 \pm 0.2 \mathrm{~b}$ & $11.6 \pm 0.9 \mathrm{a}$ & $2.6 \pm 0.2 \mathrm{c}$ & $21.3 \pm 0.5 \mathrm{ab}$ & $0.62 \pm 0.07 \mathrm{~b}$ & $23.3 \pm 1.6 \mathrm{bc}$ & $11.7 \pm 0.9 \mathrm{a}$ & $65.0 \pm 1.7 \mathrm{bc}$ \\
Aca-B & $6.6 \pm 0.3 \mathrm{a}$ & $11.6 \pm 1.3 \mathrm{a}$ & $2.5 \pm 0.2 \mathrm{bc}$ & $20.7 \pm 1.0 \mathrm{a}$ & $0.58 \pm 0.09 \mathrm{ab}$ & $21.6 \pm 2.2 \mathrm{~b}$ & $16.4 \pm 1.5 \mathrm{~b}$ & $62.0 \pm 2.7 \mathrm{~b}$ \\
Oak-B & $6.7 \pm 0.2 \mathrm{a}$ & $12.7 \pm 0.4 \mathrm{a}$ & $2.4 \pm 0.1 \mathrm{~b}$ & $21.7 \pm 0.2 \mathrm{ab}$ & $0.53 \pm 0.04 \mathrm{a}$ & $26.3 \pm 0.4 \mathrm{c}$ & $10.9 \pm 0.7 \mathrm{a}$ & $62.7 \pm 1.1 \mathrm{~b}$ \\
Chest-P & $6.8 \pm 0.2 \mathrm{ab}$ & $12.4 \pm 0.4 \mathrm{a}$ & $2.4 \pm 0.1 \mathrm{~b}$ & $21.6 \pm 0.3 \mathrm{ab}$ & $0.55 \pm 0.03 \mathrm{ab}$ & $26.1 \pm 1.1 \mathrm{c}$ & $10.8 \pm 0.7 \mathrm{a}$ & $63.0 \pm 0.7 \mathrm{~b}$ \\
Aca-P & $6.8 \pm 0.2 \mathrm{ab}$ & $12.2 \pm 0.0 \mathrm{a}$ & $2.3 \pm 0.1 \mathrm{a}$ & $21.3 \pm 0.2 \mathrm{ab}$ & $0.56 \pm 0.01 \mathrm{ab}$ & $26.1 \pm 1.1 \mathrm{c}$ & $11.7 \pm 1.1 \mathrm{a}$ & $62.3 \pm 0.4 \mathrm{~b}$ \\
Oak-P & $6.6 \pm 0.3 \mathrm{a}$ & $12.0 \pm 1.2 \mathrm{a}$ & $2.3 \pm 0.2 \mathrm{a}$ & $20.9 \pm 1.1 \mathrm{ab}$ & $0.56 \pm 0.07 \mathrm{ab}$ & $31.8 \pm 1.1 \mathrm{~d}$ & $11.8 \pm 1.2 \mathrm{a}$ & $56.4 \pm 2.3 \mathrm{a}$ \\
\hline
\end{tabular}

Control control wine, Chest-B aging in chestnut barrel for 6 months, Aca-B aging in acacia barrel for 6 months, Oak-B aging in oak barrel for 6 months, Chest- $P$ aging in contact with chestnut powder for 15 days, Aca- $P$ aging in contact with acacia powder for 15 days, Oak-P aging in contact with oak powder for 15 days

${ }^{\ddagger}$ Mean values $(n=4)$ followed by different letters on the column are significantly different $(p<0.05)$ 
of wine with wood. The decrease observed in $\mathrm{dAl}$ is consistent with previous results [28, 41, 42] and confirms the participation of monomeric anthocyanins in condensation reactions, implying a positive contribution of wood to color parameters of the wine due to the formation of more stable polymeric complexes. A greater formation of most polymerized pigments (dTAT) was observed in all wines aged in contact with powder and oak barrel, respect to control. The highest formation of stable pigments dTAT was observed in Oak-P wines, while a minor content of these stable compounds was detected when Aglianico wine was stored for 6 months in acacia and chestnut barrels (Table 1). Transformation of colorant matter during wine aging arises from the reaction between the anthocyanins, the main phenolic compounds of red wines (e.g., condensed flavanols), wood extractable phenolics (e.g., ellagitannins), aldehydes (e.g., vanillin) and numerous highly reactive products of microoxygenation occurring when wine is aged in contact with wood (e.g., acetaldehyde). As already observed in scientific literature, a greater number of polymerization reactions occur in wine in contact with chips and staves than in wine aged in barrels [9, 42-44]. Therefore, the lower the size of wood in contact with wine, the quicker the aging of wine pigments as expected, considering that a greater release of compounds (phenolics, aldehydes or ellagitannins) reacting with grape monomeric anthocyanins to form new and more stable pigments occurs. The evidence that all these transformations do not, or in a negligible amount, affect color intensity is in contrast with other results obtained on Aglianico wine aged in contact with wood [45]. The apparent contrasting results could be due to differences in initial wine phenolic composition and time of contact between wood and wine. In agreement with Alañón and co-workers [46], a slightly higher hue value was detected for Chest-B wines, due to the higher Abs420nm.
After 15 days of contact of wine with wood powders, the loss of total anthocyanins was the same observed in control wine and Chest-B and it was higher than that observed after 6 months of aging in oak and acacia barrels (Table 2). In a previous study where barrel was compared to stainlesssteel tank, a higher preservation of native $\left(\mathrm{SO}_{2}\right.$ bleaching $)$ anthocyanins after oak barrel aging was observed [28]. Also, a comparative study [43] showed that the highest concentrations of total anthocyanins were found in wine aged in barrels, followed by the wine treated with chips. This is likely due to the greater contribution of new pigments to the total content of anthocyanins (native and new pigments) in barrel aged wines. Because of in wines stored in barrels, a higher value of total phenolics was detected (Table 2), it is also possible that wood extractive ellagitannins, being more easily oxidized than other grape derived constituents [47, 48], may preserve native anthocyanins from oxidation. The absorption of anthocyanins on wood surface should be also considered [49]. Barrera Garcia and colleagues showed that the sorption processes are clearly dependent on the surface of wood that is in contact with the wine, suggesting that in traditional barrel aging, the radial-longitudinal surface of the staves in contact with wine exhibits the lowest macroporosity. In addition, in a recent study, authors [50] showed that chips particle size influences the time needed for attaining sorption equilibrium of volatile compounds from wine.

Less total tannins (proanthocyanidins) were detected in barrel aged wines and in wines in contact with Aca-P (Table 2). In previous studies, a minor content was detected in wines stored in contact with chestnut [46] and oak [51] wood. The loss is attributable to precipitation/adsorption of these molecules on wood. About the chemical nature of these molecules, it was showed that the assay used to determine total tannin content (acid-catalyzed cleavage) was mainly correlated to polymeric fraction [52]. Therefore, our results agreed with findings, showing that the polymeric fraction of
Table 2 Effect of wood aging mode on total phenolics, anthocyanins, tannins and vanillin reactive flavans (VRF) of the experimental wines (mean \pm standard deviation)

\begin{tabular}{lllll}
\hline Samples & Total phenolics $(\mathrm{mg} / \mathrm{L})^{\ddagger}$ & $\begin{array}{l}\text { Total anthocya- } \\
\text { nins }(\mathrm{mg} / \mathrm{L})^{\ddagger}\end{array}$ & Total tannins $(\mathrm{mg} / \mathrm{L})^{\ddagger}$ & VRF $(\mathrm{mg} / \mathrm{L})^{\ddagger}$ \\
\hline Control & $4117 \pm 261 \mathrm{a}$ & $515 \pm 27 \mathrm{a}$ & $7.400 \pm 0.816 \mathrm{c}$ & $2290 \pm 28 \mathrm{c}$ \\
Chest-B & $6498 \pm 90 \mathrm{c}$ & $526 \pm 9 \mathrm{a}$ & $6.193 \pm 0.238 \mathrm{~b}$ & $2018 \pm 85 \mathrm{a}$ \\
Aca-B & $6660 \pm 40 \mathrm{c}$ & $577 \pm 39 \mathrm{~b}$ & $6.250 \pm 0.714 \mathrm{ab}$ & $2349 \pm 93 \mathrm{c}$ \\
Oak-B & $6686 \pm 25 \mathrm{c}$ & $597 \pm 14 \mathrm{~b}$ & $5.303 \pm 0.090 \mathrm{a}$ & $2036 \pm 10 \mathrm{~b}$ \\
Chest-P & $4529 \pm 125 \mathrm{~b}$ & $508 \pm 21 \mathrm{a}$ & $6.750 \pm 1.121 \mathrm{bc}$ & $1944 \pm 81 \mathrm{~b}$ \\
Aca-P & $4346 \pm 263 \mathrm{ab}$ & $525 \pm 20 \mathrm{a}$ & $6.063 \pm 0.472 \mathrm{ab}$ & $2030 \pm 87 \mathrm{~b}$ \\
Oak-P & $4468 \pm 6 \mathrm{~b}$ & $518 \pm 30 \mathrm{a}$ & $6.600 \pm 0.529 \mathrm{bc}$ & $1889 \pm 87 \mathrm{a}$ \\
\hline
\end{tabular}

Control control wine, Chest-B aging in chestnut barrel for 6 months, Aca-B aging in acacia barrel for 6 months, Oak-B aging in oak barrel for 6 months, Chest-P aging in contact with chestnut powder for 15 days, Aca- $P$ aging in contact with acacia powder for 15 days, Oak-P aging in contact with oak powder for 15 days

${ }^{\ddagger}$ Mean values $(n=4)$ followed by different letters on the column are significantly different $(p<0.05)$ 
proanthocyanidins decreased due to aging in wood $[51,53]$. With exception of Aca-B, a decrease of VRF was detected in all wood aged wines (Table 2). This parameter is a measure of low-molecular-weight condensed tannins and its decrease was correlated with wine aging and micro-oxygenation [54, 55]. This trend agrees with a previous study [56] which showed that, in model solution, (+)-catechin and (-)-epicatechin tend to disappear from a model wine in presence of oak wood, to reach an equilibrium after 20 days of contact.

Changes in the evolution of phenolic acids (hydroxybenzoic and hydroxycinnamic) during aging of wine in contact with wood were widely reported [12, 27]. The most abundant is gallic acid and its content is higher in aged wines, because it is released by the hydrolysis of gallate esters of hydrolysable tannins released from wood $[23,57]$. A lower content of gallic acid was detected in Aca-B wines, while the other wood aged wines did not differ from the control wine (Table 3). In contrast with these results, a greater extraction of gallic acid from chestnut than from oak was reported in the literature $[27,58,59]$. A significant higher content of caffeic acid was detected only in Chest-P, while $p$-coumaric acid levels were higher in wines stored in oak barrels and in contact with all the considered powders (Oak-P, Chest-P and Aca-P). Caffeic and $p$-coumaric acid in wine can originate from the hydrolysis of grape precursors (e.g., caftaric and coutaric acid) and, when wine is stored in contact with wood, they can derive from the hydroalcoholysis of oak wood [7]. This effect was found to be species dependent for caffeic and $p$-coumaric acids [27]. Although a previous study [31] found that $p$-coumaric acid can be used (together with other phenolic compounds) as a chemical marker of wood used in wine aging, in our study, no clear differentiation among chestnut and acacia was observed, while wines aged in contact with oak clearly differentiate from others for this parameter (Table 3). Wines aged in contact with acacia wood (barrel and powder) showed higher content of protocatechuic acid (Table 3). This was not confirmed by comparative data on acacia, oak and chestnut reported in the literature [27]. Anyway, the same authors [27] also observed that when the same wine was aged in different woods a defined behavior related to wood species could not be established. Wines Aca-B, Oak-B and Chest-P showed higher content of vanillic acid, a wood derivative, while less content was detected in Aca-P, and Oak-P. Del Alamo and co-workers [19] showed that during barrel aging these compounds increased during the first 7 months of aging and then decreased, while no effect of wood size was observed. In contrast, in a recent study, higher levels were detected in wines aged with chips and micro-oxygenated than in those aged with staves and micro-oxygenated [13]. A great variability in the content of syringic acid of wines in contact with powders obtained from different wood species was detected (Table 3). Del Alamo and co-workers [12] reported a small increase of syringic acid during the aging period and also a significant effect of wood species and size on the content of this compound in red wines during aging was found [27]. As syringic acid origin from wood hydroalcoholysis, it may be that the size of wood affected its release in wine.

When ANOVA was applied to these data taking into account the two factors, wood species and aging modality (barrel or powder), the highest $\mathrm{F}$ values were obtained for total phenolics, total anthocyanins, dTAT, dAl, $p$-coumaric acid, syringic acid, VRF, Abs620nm and total tannins, all related to aging mode (Table 4 ). The parameters mainly affected by wood species were instead protocatechuic acid, syringic acid, dAl, dTAT, VRF, dAT and total anthocyanins (Table 4).

As expected, the Principal Component Analysis (PCA) of phenolics and chromatic characteristics showed that samples differed and tended to be grouped together according to the wood aging mode (Fig. 1). The PCA was performed on all samples and variables that resulted significantly affected by the considered factors (anthocyanins, total phenolics, vanillic acid, Abs620nm, protocatechuic acid, dAT,

Table 3 Effect of wood aging mode on phenolic acid level $(\mathrm{mg} / \mathrm{L})$ of the experimental wines (mean \pm standard deviation)

\begin{tabular}{llllllc}
\hline Samples & Caffeic acid & $p$-Coumaric acid & Gallic acid & Protocatechuic acid $^{\ddagger}$ & Vanillic acid $^{\ddagger}$ & Syringic acid $^{\ddagger}$ \\
\hline Control & $6.38 \pm 0.88 \mathrm{~b}$ & $2.06 \pm 0.36 \mathrm{a}$ & $40.65 \pm 5.19 \mathrm{~b}$ & $1.88 \pm 0.35 \mathrm{a}$ & $3.79 \pm 0.21 \mathrm{bc}$ & $1.79 \pm 0.14 \mathrm{ab}$ \\
Chest-B & $5.27 \pm 0.47 \mathrm{a}$ & $1.89 \pm 0.28 \mathrm{a}$ & $45.32 \pm 7.44 \mathrm{~b}$ & $2.49 \pm 0.38 \mathrm{ab}$ & $3.12 \pm 0.37 \mathrm{~b}$ & $1.39 \pm 0.29 \mathrm{a}$ \\
Aca-B & $7.20 \pm 0.88 \mathrm{bc}$ & $2.71 \pm 0.36 \mathrm{a}$ & $36.00 \pm 3.61 \mathrm{a}$ & $3.32 \pm 0.37 \mathrm{~b}$ & $4.77 \pm 0.58 \mathrm{c}$ & $2.18 \pm 0.19 \mathrm{~b}$ \\
Oak-B & $5.71 \pm 0.42 \mathrm{a}$ & $5.33 \pm 0.73 \mathrm{~b}$ & $37.23 \pm 5.90 \mathrm{ab}$ & $1.82 \pm 0.38 \mathrm{a}$ & $4.49 \pm 0.38 \mathrm{c}$ & $1.41 \pm 0.29 \mathrm{a}$ \\
Chest-P & $8.45 \pm 1.09 \mathrm{c}$ & $5.76 \pm 0.96 \mathrm{~b}$ & $43.12 \pm 3.38 \mathrm{~b}$ & $1.92 \pm 0.22 \mathrm{a}$ & $4.88 \pm 0.93 \mathrm{c}$ & $1.53 \pm 0.17 \mathrm{a}$ \\
Aca-P & $5.61 \pm 0.57 \mathrm{a}$ & $5.27 \pm 0.45 \mathrm{~b}$ & $42.38 \pm 2.30 \mathrm{~b}$ & $3.01 \pm 0.48 \mathrm{~b}$ & $1.61 \pm 0.18 \mathrm{a}$ & $5.33 \pm 0.44 \mathrm{~d}$ \\
Oak-P & $6.24 \pm 0.35 \mathrm{ab}$ & $6.39 \pm 0.69 \mathrm{~b}$ & $41.80 \pm 1.58 \mathrm{~b}$ & $1.77 \pm 0.41 \mathrm{a}$ & $1.93 \pm 0.34 \mathrm{a}$ & $4.34 \pm 0.64 \mathrm{c}$ \\
\hline
\end{tabular}

Control control wine, Chest-B aging in chestnut barrel for 6 months, Aca-B aging in acacia barrel for 6 months, Oak-B aging in oak barrel for 6 months, Chest- $P$ aging in contact with chestnut powder for 15 days, Aca- $P$ aging in contact with acacia powder for 15 days, Oak-P aging in contact with oak powder for 15 days

${ }^{\ddagger}$ Mean values $(n=4)$ followed by different letters on the column are significantly different $(p<0.05)$ 
Table $4 \mathrm{~F}$ values and significance of variables wood species (oak, chestnut, acacia) and aging mode (barrel, powders) for main phenolic compounds and chromatic characteristics

\begin{tabular}{|c|c|c|c|c|c|c|c|c|c|c|c|c|c|c|}
\hline & \multicolumn{2}{|c|}{ Anthocyanins } & \multicolumn{2}{|c|}{ Total phenolics } & \multicolumn{2}{|c|}{ Tannins } & \multicolumn{2}{|l|}{ VRF } & \multicolumn{2}{|c|}{$\mathrm{Abs}_{420 \mathrm{~nm}}$} & \multicolumn{2}{|c|}{$\mathrm{Abs}_{520 \mathrm{~nm}}$} & \multicolumn{2}{|c|}{$\mathrm{Abs}_{620 \mathrm{~nm}}$} \\
\hline & $F$ & $p>F$ & $F$ & $p>F$ & $F$ & $p>F$ & $F$ & $p>F$ & $F$ & $p>F$ & $F$ & $p>F$ & $F$ & $p>F$ \\
\hline Wood species ${ }^{\mathbf{a}}$ & 3.526 & 0.049 & 0.021 & 0.979 & 0.709 & 0.504 & 7.962 & 0.003 & 1.906 & 0.175 & 0.859 & 0.438 & 2.079 & 0.151 \\
\hline \multirow[t]{3}{*}{ Aging mode ${ }^{\mathbf{b}}$} & 26.788 & $<0.0001$ & 889.984 & $<0.0001$ & 5.532 & 0.029 & 8.680 & 0.008 & 0.095 & 0.761 & 1.151 & 0.296 & 8.500 & 0.009 \\
\hline & \multicolumn{3}{|c|}{ Color intensity } & \multicolumn{2}{|c|}{ Hue } & \multicolumn{3}{|l|}{ dTAT } & \multicolumn{3}{|c|}{ dAl } & \multicolumn{3}{|c|}{ dAT } \\
\hline & \multicolumn{2}{|l|}{$F$} & $p>F$ & $F$ & $p>F$ & \multicolumn{2}{|l|}{$F$} & $p>F$ & \multicolumn{2}{|l|}{$F$} & $p>F$ & \multicolumn{2}{|l|}{$F$} & $p>F$ \\
\hline Wood species ${ }^{\mathbf{a}}$ & \multicolumn{2}{|c|}{0.852} & 0.441 & 0.981 & 0.392 & \multicolumn{2}{|c|}{8.959} & 0.002 & \multicolumn{2}{|c|}{13.341} & 0.000 & \multicolumn{2}{|c|}{4.970} & 0.018 \\
\hline \multirow[t]{3}{*}{ Aging mode ${ }^{\mathbf{b}}$} & \multicolumn{2}{|c|}{0.271} & & .137 & 0.299 & \multicolumn{2}{|c|}{16.191} & 0.001 & \multicolumn{2}{|c|}{12.226} & 0.002 & \multicolumn{2}{|c|}{3.909} & 0.062 \\
\hline & \multicolumn{2}{|c|}{ Caffeic acid } & \multicolumn{2}{|c|}{$p$-Coumaric acid } & \multicolumn{2}{|c|}{ Gallic acid } & Protoc & atechuic & acid & Vanilli & acid & Syrir & gic acid & \\
\hline & $F$ & $p>F$ & $F$ & $p>F$ & $F$ & $p>F$ & $F$ & $p>$ & & $F$ & $p>F$ & $F$ & & $>F$ \\
\hline Wood species ${ }^{\mathbf{a}}$ & 1.205 & 0.321 & 2.929 & 0.077 & 2.850 & 0.081 & 25.360 & $<0$ & 0001 & 1.762 & 0.197 & 20.8 & & 0.0001 \\
\hline Aging mode ${ }^{\mathbf{b}}$ & 1.606 & 0.220 & 11.912 & 0.003 & 2.285 & 0.146 & 3.326 & 0.08 & & 1.365 & 0.256 & 11.4 & & 003 \\
\hline
\end{tabular}

${ }^{\text {a}}$ Wood species: oak, acacia, chestnut

${ }^{\text {b}}$ Aging mode: powders 15 days, barrels 6 months

VRF, dAl, total tannins, syringic acid, $p$-coumaric acid and dTAT) with the aim of obtaining the relationships among the studied parameters and wine aging conditions (Fig. 1). Two principal components (PC1 and PC2) were considered. They accounted for $68.61 \%$ of the variability of the original data set (Fig. 1). PC1 explained most of the variability $(48.10 \%)$, while only $20.51 \%$ was accounted by PC2. PC1 was defined by major differences between values recorded on wines aged in barrels and those aged in contact with wood powders. Wines aged in barrels differentiated from wines aged in contact with powders, because they were more correlated to parameters Abs620 nm, vanillic acid, and content of total phenolics and anthocyanins. Barrel aged wines were well grouped in the first quadrant, while control wine was mainly correlated to the parameters dAl, dAT and VRF. Syringic acid and $p$-coumaric acid resulted, instead, to be characteristic of wines aged in contact with powders.

\section{Effect on sensory profiles}

It was previously found that the aging of a red wine with different kind of wood (for botanical species and size) may determine great differences in its sensory profile $[25,26$, 60]. For a determined wine variety, the knowledge of the sensory outcome of different modalities of wood aging is very important to choose the most suitable for the desired wine style. Figure 2 reports the sensory profiles obtained for the experimental wines. The analysis of variance found that the taste profile (acidity, sweetness, bitterness) and astringency did not show significant differences among the tested aging modes. On the contrary, the odor profiles differed significantly. The odor descriptors evaluated, generated by consensus, were: cherry, red fruits, coffee, smoky, toasty vanilla, black pepper, woody, butter. The different aging methods induced a clear differentiation in the sensory profile of Aglianico wine. All the evaluated odor descriptors, except "butter" and "cherry", resulted to be significantly different among the tested aging modalities. The contribution with wood character to wine aroma was very different for the different tested modalities. The wine aged in contact with oak wood (Oak-B and Oak-P) showed the strongest and most complex wood character. In particular, the wine aged in oak barrels (Oak-B) obtained significantly higher scores for "coffee", "smoky", "toasty", "black pepper" and "woody" odor descriptors (Fig. 2). Acacia and chestnut barrels (Aca-B and Chest-B) gave a minor contribution, consisting essentially in the enrichment by "vanilla" and "woody" notes (Fig. 2). Other authors also reported that acacia and chestnut barrels are less 'aggressive' than oak and add less wood character to wine [26, 61]. Among wood powders, oak powder (Oak-P) had the highest impact on wood character, by conferring "smoky", "toasty" and "black pepper" notes (Fig. 2), although at a lesser extent than oak barrel. Chestnut and acacia powders (Chest-P and Aca-P) were the treatments that overall had the lowest sensory impact, by conferring "woody" and "smoky" notes the former, and a "coffee" note the latter (Fig. 2). Previous studies comparing barrel and chips aging found a higher level of wood volatile compounds (furfural, syringaldehyde, vanillin, guaiacol) in wines treated with chips [44]. This result seems to be in contrast with our sensory results, as a higher sensory impact of wood was expected in wines aged by powder contact. However, also adsorption phenomena of volatiles by wood should be considered; in particular, it was found that wood particle 
Biplot (PC1 and PC2: $68.61 \%$ )

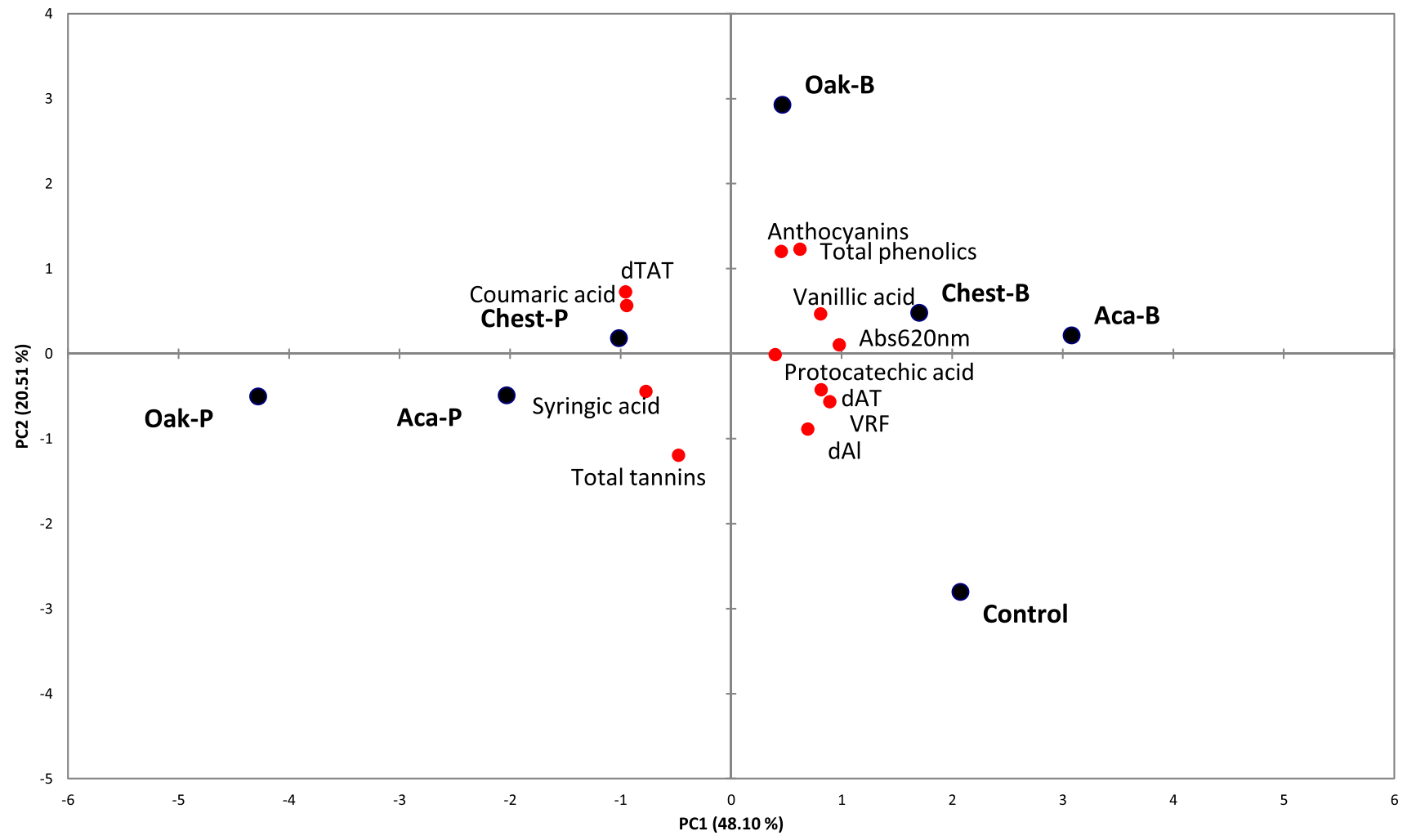

Fig. 1 Principal Component Analysis (biplot of PC1 and PC2) of phenolics and chromatic characteristics of Aglianico wines obtained by the different wood aging modes. Control control wine, Chest- $B$ aging in chestnut barrel for 6 months, Aca-B aging in acacia barrel for 6 months, Oak-B aging in oak barrel for 6 months, Chest- $P$ aging in contact with chestnut powder for 15 days, Aca-P aging in contact with acacia powder for 15 days, Oak-P aging in contact with oak powder for 15 days
Fig. 2 Sensory profiles of Aglianico wines obtained by the different wood aging modes. Control control wine, Chest- $B$ aging in chestnut barrel for 6 months, Aca- $B$ aging in acacia barrel for 6 months, $O a k-B$ aging in oak barrel for 6 months, Chest- $P$ aging in contact with chestnut powder for 15 days, Aca- $P$ aging in contact with acacia powder for 15 days, Oak- $P$ aging in contact with oak powder for 15 days. Asterisks near the descriptors indicate statistically significant differences $(p<0.05)$

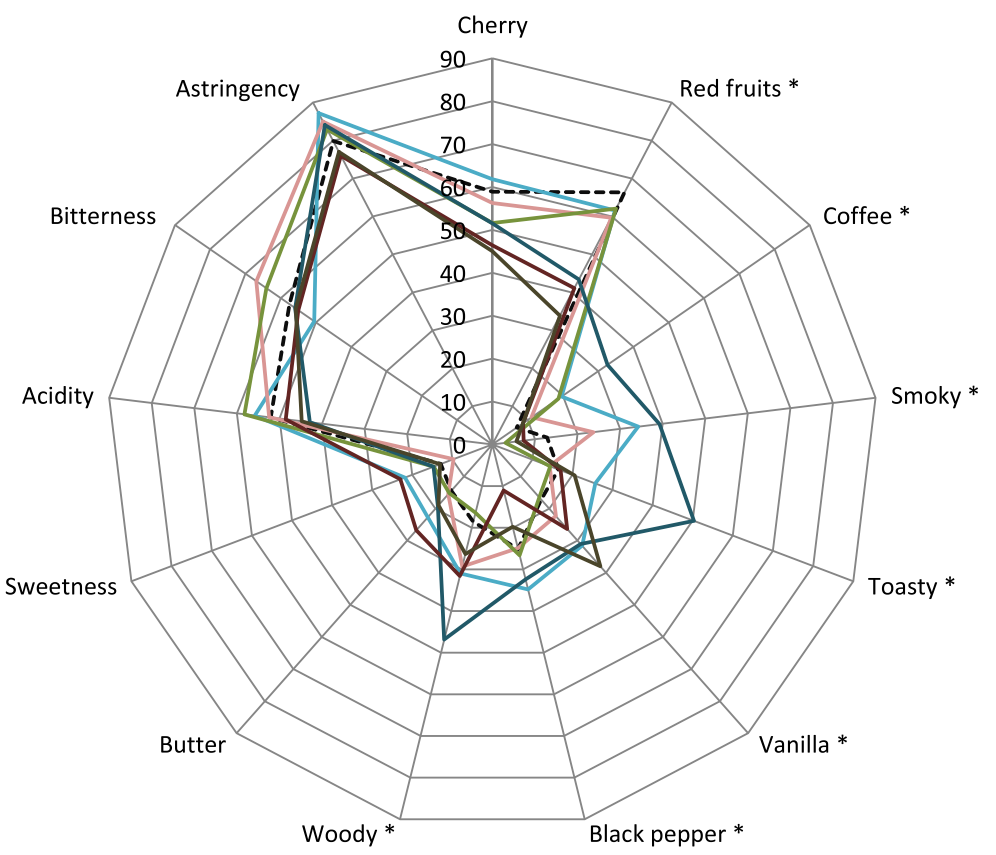

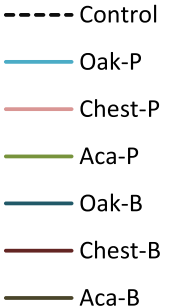


size affects the time needed for attaining equilibrium [50]. The kinetics of desorption/adsorption in relation to the ratio exposed surface/wine has never been investigated for wood powders. Moreover, it should be considered that the final sensory outcome also depends on perceptive interactions that may occur among sensory active compounds [62-64]. The scores obtained for "red fruit" descriptor clearly differentiated the three wines aged in barrels (Oak-B, Aca-B and Chest-B) from the wine aged in contact with wood powders (Oak-P, Aca-P and Chest-P). These last obtained higher scores, that were not different from the control wine in stainless-steel tank (Fig. 2). Different concurrent phenomena may have contributed in modulating red fruit odor in the experimental wines: on one hand, the enrichment of wine with volatile compounds released by wood that may have a masking effect on fruity odor when present at suprathreshold concentrations [62], but also a synergistic effect if present at sub-threshold and peri-threshold levels [63]; on the other hand, the adsorption of fruity esters by wood may occur at various extent depending on wine and wood composition $[65,66]$. In complex, our results showed that only the aging in barrels (oak, chestnut and acacia) determined a decrease of red fruit odor with respect to control wine, while the treatment with oak and chestnut powders preserved the fruity character of Aglianico wine, but in the meanwhile, it added complexity by conferring non-dominant woody notes.

The results of the descriptive sensory analysis showed that the tested treatments differed essentially in their effect on odor profile of wine. To understand at a glance how the different aging modalities can modulate the sensory style of Aglianico wine, a Principal Component Analysis (PCA) was carried out on the quantitative data of the odor profiles. Figure 3 reports the loading plot of the first two component extracted, PC1 and PC2. These two components explained $80.20 \%$ of the total variance (PC1 $44.88 \%$ and PC2 35.32\%). Considering the squared cosines, the positive semiaxis of PC1 represents a "woody-toasty" dimension as it was the most strongly correlated with the variables "coffee", "smoky", "toasty", "woody" and "vanilla" (Fig. 3). The positive semiaxis of PC2 represents a "fruity-spicy" dimension, as it was the most strongly correlated with "red fruits", "cherry", "black pepper", while the negative semiaxis of PC2 was mostly correlated to "butter" odor (Fig. 3). The wines aged in contact with oak wood (barrels and powders) were the most positively correlated with $\mathrm{PC} 1$, and therefore, they were the ones in which the "woody-toasty" character

Biplot (PC1 and PC2: $80.20 \%$ )

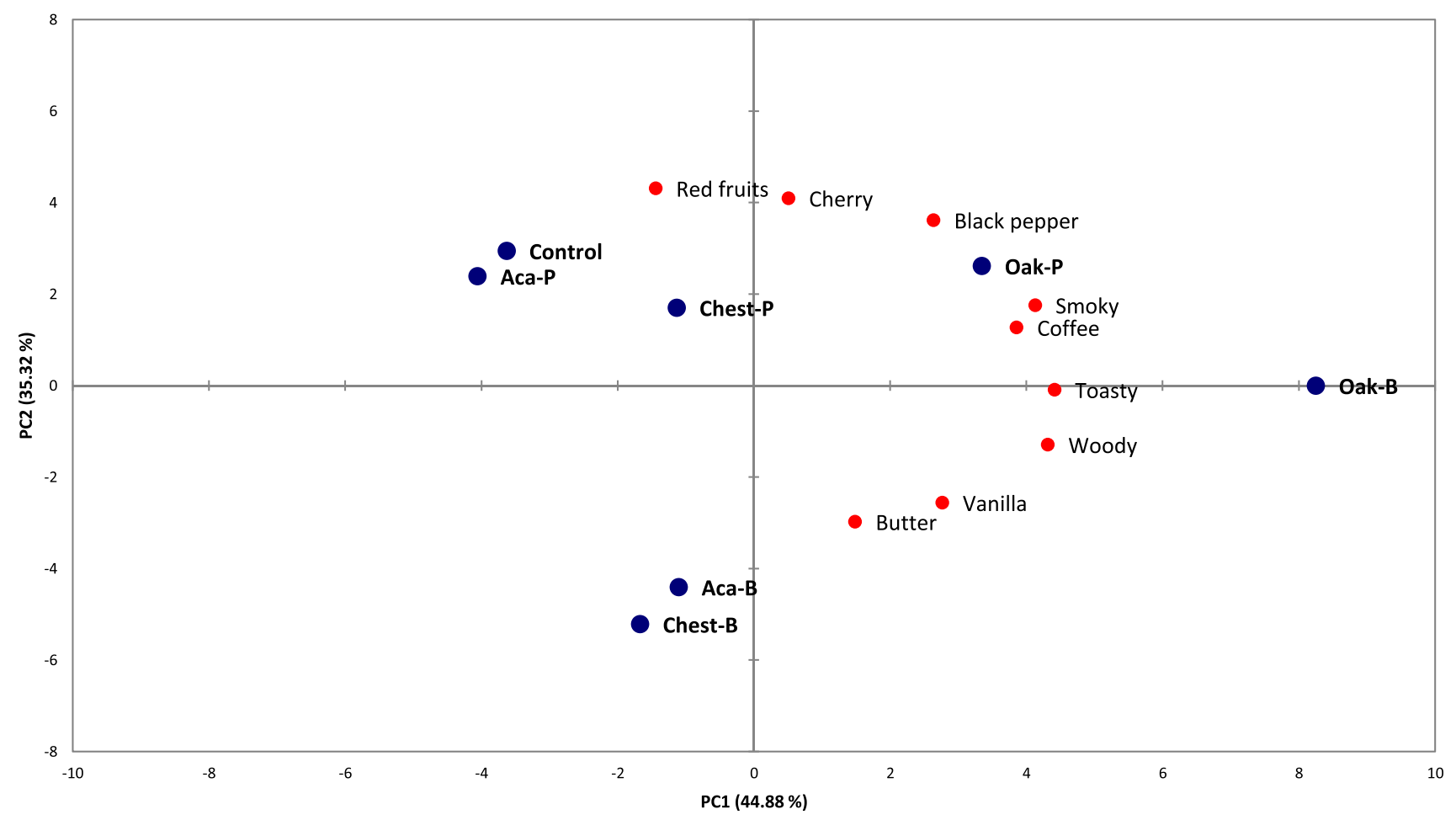

Fig. 3 Principal Component Analysis (biplot of PC1 and PC2) of sensory data of Aglianico wines obtained by the different wood aging modes. Control control wine, Chest- $B$ aging in chestnut barrel for 6 months, $A c a-B$ aging in acacia barrel for 6 months, Oak-B aging in oak barrel for 6 months, Chest-P aging in contact with chestnut powder for 15 days, Aca- $P$ aging in contact with acacia powder for 15 days, Oak-P aging in contact with oak powder for 15 days 
was more expressed, mostly in Oak-B (Fig. 3). It is interesting to note that the use of oak powders conferred to wine a wood character as complex as oak barrels, but less intense. The wines aged in acacia and chestnut barrels (Aca-B and Chest-B) were mostly correlated to "vanilla" and "butter" odors (Fig. 3), thus showing a "sweeter" wood character. The strongest correlation with the fruity dimension was shown by control wine (Control) and wines aged in contact with acacia and chestnut powders (Aca-P and Chest-P) (Fig. 3). From the results of PCA, it is evident that the tested modalities of wood contact allow to impart to Aglianico wine different sensory styles. Indeed, it is possible to hypothesize a scale of "wood impact" for Aglianico wine as follows: oak barrel $>$ oak powder $>$ acacia and chestnut barrels $>$ chestnut powder $>$ acacia powder.

\section{Conclusions}

The results of the present study indicate that the use of wood powders could be an easy-to-use alternative to barrels for red wine aging. Some parameters linked to the pigments (free anthocyanins and anthocyanins combined with tannins bleachable by $\mathrm{SO}_{2}$ ) and low-molecular-weight tannins, as well as syringic acid and $p$-coumaric acid resulted to be more correlated to wines aged in contact with all the tested powders (oak, acacia and chestnut). In regards of the two variables considered in this study (wood size and wood botanical origin), phenolic compounds and chromatic characteristics allowed a differentiation based on the size of wood in contact with wine. As concerns sensory profiles, oak wood gave the strongest and most complex wood character to wine, most of all barrels and powder at a lesser extent. Acacia and chestnut barrels gave a minor contribution, consisting essentially in a slight enrichment by vanilla odor and a generic woody note. Chestnut and acacia powders were the treatments that overall had the lowest sensory impact. In general, the use of all the wood powders allowed to preserve the dominance of red fruit odors of Aglianico wine. The combination of these results suggests that the use of barrels from alternative woods and of wood powders may represent an oenological tool to modulate the impact of woody, toasty, and spicy odors in the sensory profile, thus allowing to better adapt wood aging to the desired wine style. Powders in particular may represent a fast treatment to improve wine color stability by wood contact, without conferring a dominant wood character to wine. Moreover, the use of wood powders could allow to increase the sustainability of winemaking process, by re-using a by-product of cooperage.

Acknowledgements We thank Mr. F. Colandrea and Taburno winery of Foglianise for the experimental vinifications.
Funding Open access funding provided by Università degli Studi di Napoli Federico II within the CRUI-CARE Agreement. This research did not receive any specific grant from funding agencies in the public, commercial, or not-for-profit sectors.

Availability of data and materials Data are available by contacting the authors.

\section{Compliance with ethics requirements}

Conflicts of interest The authors declare that they have no conflicts of interest.

Ethical statement Sensory analysis was performed in compliance with "IFST Guidelines for Ethical and Professional Practices for the Sensory Analysis of Foods".

Open Access This article is licensed under a Creative Commons Attribution 4.0 International License, which permits use, sharing, adaptation, distribution and reproduction in any medium or format, as long as you give appropriate credit to the original author(s) and the source, provide a link to the Creative Commons licence, and indicate if changes were made. The images or other third party material in this article are included in the article's Creative Commons licence, unless indicated otherwise in a credit line to the material. If material is not included in the article's Creative Commons licence and your intended use is not permitted by statutory regulation or exceeds the permitted use, you will need to obtain permission directly from the copyright holder. To view a copy of this licence, visit http://creativecommons.org/licenses/by/4.0/.

\section{References}

1. Garde-Cerdán T, Ancín-Azpilicueta C (2006) Review of quality factors on wine ageing in oak barrels. Trends Food Sci Tech 17:438-447

2. Peterson AL, Waterhouse AL (2016) 1H NMR: a novel approach to determining the thermodynamic properties of acetaldehyde condensation reactions with glycerol, $(+)$-catechin, and glutathione in model wine. J Agr Food Chem 64:6869-6878

3. He F, Liang NN, Mu L, Pan QH, Wang J, Reeves MJ, Duan CQ (2012) Anthocyanins and their variation in red wines II. Anthocyanin derived pigments and their color evolution. Molecules 17:1483-1519

4. Remy S, Fulcrand H, Labarbe B, Cheynier V, Moutounet M (2000) First confirmation in red wine of products resulting from direct anthocyanin-tannin reactions. J Sci Food Agr 80:745-751

5. Atanasova V, Fulcrand H, Cheynier V, Moutounet M (2002) Effect of oxygenation on polyphenol changes occurring in the course of wine-making. Anal Chim Acta 458:15-27

6. Llaudy del Carmen M, Canals R, González-Manzano S, SantosBuelga CJM, C, Zamora F, (2006) Influence of micro-oxygenation treatment before oak aging on phenolic compounds composition, astringency, and color of red wine. J Agr Food Chem 54:4246-4252

7. de Simón BF, Cadahía E, Conde E, García-Vallejo MC (1999) Ellagitannins in woods of Spanish, French and American oaks. Holzforschung 53:147-150

8. Rinaldi A, Gambuti A, Moine-Ledoux V, Moio L (2010) Evaluation of the astringency of commercial tannins by means of the SDS-PAGE-based method. Food Chem 122:951-956 
9. Jourdes M, Michel J, Saucier C, Quideau S, Teissedre PL (2011) Identification, amounts, and kinetics of extraction of C-glucosidic ellagitannins during wine aging in oak barrels or in stainless steel tanks with oak chips. Anal Bioanal Chem 401:1531-1539

10. Picariello L, Gambuti A, Picariello B, Moio L (2017) Evolution of pigments, tannins and acetaldehyde during forced oxidation of red wine: effect of tannins addition. LWT 77:370-375

11. Chassaing S, Lefeuvre D, Jacquet R, Jourdes M, Ducasse L, Gallan S, Grelard A, Saucier C, Teissedre P-L, Dangles O, Quideau S (2010) Physicochemical studies of new Anthocyano-Ellagitannin hybrid pigments: about the origin of the influence of Oak C-Glycosidic ellagitannins on wine color. Eur J Org Chem 2010:55-63

12. Del Álamo SM, Nevares I, Cárcel L, Navas L (2004) Analysis for low molecular weight phenolic compounds in a red wine aged in oak chips. Anal Chim Acta 513:229-237

13. Martínez-Gil AM, del Alamo-Sanza M, Nevares I, SánchezGómez R, Gallego L (2020) Effect of size, seasoning and toasting level of Quercus pyrenaica Willd. wood on wine phenolic composition during maturation process with micro-oxygenation. Food Res Int 128:108703

14. Gómez-Plaza E, Pérez-Prieto LJ, Martínez-Cutillas A, LópezRoca JM (2004) Color and phenolic compounds of oak-matured wines as affected by the characteristics of the barrel, in Red wine color, ed. by Waterhouse AL and Kennedy JA. ACS Symp Ser 886:22-34

15. Garde-Cerdán T, Mozaz SR, Azpilicueta CA (2002) Volatile composition of aged wine in used barrels of French oak and of American oak. Food Res Int 35:603-610

16. Sefton MA, Francis IL, Pocock KF, Williams PJ (1993) The influence of natural seasoning on the concentrations of eugenol, vanillin, and cis-and trans- $\beta$-methyl- $\gamma$-octalactone extracted from French and American oakwood. Sci Aliment 13:629-643

17. Chatonnet P, Boidron JN, Pons M (1989) Effect on heat on oak wood and its chemical composition. Part 2. Variations of certain compounds in relation to toasting intensity. Conn Vigne Vin 23:223-250

18. Cadahía E, Fernández de Simón B, Jalocha J (2003) Volatile compounds in Spanish, French, and American oak woods after natural seasoning and toasting. J Agr Food Chem 51:5923-5932

19. Del Alamo SM, Escudero JF, De Castro TR (2004) Changes in phenolic compounds and colour parameters of red wine aged with oak chips and in oak barrels. Food Sci Technol Int 10:233-241

20. Suárez R, Suárez-Lepe JA, Morata A, Calderón F (2007) The production of ethylphenols in wine by yeasts of the genera Brettanomyces and Dekkera: a review. Food Chem 102:10-21

21. Lisanti MT, Gambuti A, Genovese A, Piombino P, Moio L (2017) Treatment by fining agents of red wine affected by phenolic offodour. Eur Food Sci Technol 243:501-510

22. Bautista-Ortín AB, Lencina AG, Cano-López M, Pardo-Mínguez F, López-Roca JM, Gómez-Plaza, E (2008) The use of oak chips during the ageing of a red wine in stainless steel tanks or used barrels: effect of the contact time and size of the oak chips on aroma compounds. Aust J Grape Wine R 14:63-70

23. Martínez-Gil A, del Alamo-Sanza M, Sánchez-Gómez R, Nevares I (2020) Alternative woods in enology: characterization of tannin and low molecular weight phenol compounds with respect to traditional oak woods. A review. Molecules 25:1474

24. Koussissi E, Dourtoglou VG, Ageloussis G, Paraskevopoulos Y, Dourtoglou T, Paterson A, Chatzilazarou A (2009) Influence of toasting of oak chips on red wine maturation from sensory and gas chromatographic headspace analysis. Food Chem 114:1503-1509

25. Tavares M, Jordão AM, Ricardo-da-Silva JM (2018) Impact of cherry, acacia and oak chips on red wine phenolic parameters and sensory profile. OENO One 51:329-342

26. Fernández de Simón B, Martínez J, Sanz M, Cadahía E, Muñoz EE, AM, (2014) Volatile compounds and sensorial characterisation of red wine aged in cherry, chestnut, false acacia, ash and oak wood barrels. Food Chem 147:346-356

27. Fernández De Simón B, Sanz M, Cadahía E, Martínez J, Esteruelas E, Muñoz AM (2014) Polyphenolic compounds as chemical markers of wine ageing in contact with cherry, chestnut, false acacia, ash and oak wood. Food Chem 143:66-76

28. Gambuti A, Capuano R, Lisanti MT, Strollo D, Moio L (2010) Effect of aging in new oak, one-year-used oak, chestnut barrels and bottle on color, phenolics and gustative profile of three monovarietal red wines. Eur Food Sci Technol 231:455-465

29. De Rosso M, Panighel A, Dalla Vedova A, Stella L, Flamini R (2009) Changes in chemical composition of a red wine aged in acacia, cherry, chestnut, mulberry, and oak wood barrels. J Agr Food Chem 57:1915-1920

30. Flamini R, Vedova AD, Cancian D, Panighel A, De Rosso M (2007) GC/MS-positive ion chemical ionization and MS/MS study of volatile benzene compounds in five different woods used in barrel making. J Mass Spectrom 42:641-646

31. Sanz M, de Simón BF, Cadahía E, Esteruelas E, Muñoz ÁM, Hernández MT, Estrella I (2012) Polyphenolic profile as a useful tool to identify the wood used in wine aging. Anal Chim Acta 732:33-45

32. Alañón ME, Schumacher R, Castro-Vázquez L, Díaz-Maroto IJ, Díaz-Maroto MC, Pérez-Coello MS (2013) Enological potential of chestnut wood for aging Tempranillo wines part I: Volatile compounds and sensorial properties. Food Res Int 51:325-334

33. Glories Y (1984) La couleur des vins rouges. $1^{\circ}$ e $2^{\circ}$ partie. Conn Vigne Vin 18:253-271

34. Ribéreau-Gayon P, Stonestreet E (1965) Le dosage des anthocyanes dans les vins rouges. Bull Soc Chim France 9:2649-2652

35. Ribéreau-Gayon P, Stonestreet E (1966) Dosage des tanins du vin rouge et détermination de leur structure. Chimie Analytique 48:188

36. Di Stefano R, Cravero MC, Gentilini N (1989) Metodi per lo studio dei polifenoli dei vini. L'Enotecnico 25:83-89

37. Fernández de Simón B, Hernández T, Cadahía E, Dueñas M, Estrella I (2003) Phenolic compounds in a Spanish red wine aged in barrels made of Spanish, French and American oak wood. Eur Food Sci Technol 216:150-156

38. Dravnieks A (1985) Atlas of odor character profiles. American Society for Testing and Materials, Philadelphia

39. Nevares I, Crespo R, Gonzalez C, del Alamo-Sanza M (2014) Imaging of oxygen transmission in the oak wood of wine barrels using optical sensors and a colour camera. Aust G Grape Wine R 20:353-360

40. Cano-López M, López-Roca JM, Pardo-Mínguez F, Plaza EG (2010) Oak barrel maturation vs. micro-oxygenation: Effect on the formation of anthocyanin-derived pigments and wine colour. Food Chem 119:191-195

41. Kyraleou M, Kallithraka S, Chira K, Tzanakouli E, Ligas I, Kotseridis Y (2015) Differentiation of wines treated with wood chips based on their phenolic content, volatile composition, and sensory parameters. J Food Sci 80:C2701-C2710

42. Kyraleou M, Tzanakouli E, Kotseridis Y, Chira K, Ligas I, Kallithraka S, Teissedre PL (2016) Addition of wood chips in red wine during and after alcoholic fermentation: Differences in color parameters, phenolic content and volatile composition. OENO One 50:209-222

43. Del Álamo M, Nevares I, Gallego L, Martin C, Merino S (2008) Aging markers from bottled red wine aged with chips, staves and barrels. Anal Chim Acta 621:86-99

44. Arapitsas P, Antonopoulos A, Stefanou E, Dourtoglou VG (2004) Artificial aging of wines using oak chips. Food Chem 86:563-570

45. Gambuti A, Strollo D, Erbaggio A, Lecce L, Moio L (2007) Effect of winemaking practices on color indexes and selected bioactive phenolics of Aglianico wine. J Food Sci 72:S623-S628 
46. Alañón ME, Schumacher R, Castro-Vázquez L, Díaz-Maroto MC, Hermosín-Gutiérrez I, Pérez-Coello MS (2013) Enological potential of chestnut wood for aging Tempranillo wines Part II: Phenolic compounds and chromatic characteristics. Food Res Int 51:536-543

47. Barbehenn RV, Jones CP, Hagerman AE, Karonen M, Salminen JP (2006) Ellagitannins have greater oxidative activities than condensed tannins and galloyl glucoses at high $\mathrm{pH}$ : potential impact on caterpillars. J Chem Ecol 32:2253-2267

48. Vivas N, Glories Y (1996) Role of oak wood ellagitannins in the oxidation process of red wines during aging. Am J Enol Viticult 47:103-107

49. Barrera-García VD, Gougeon RD, Di Majo D, De Aguirre C, Chassagne VA, D, (2007) Different sorption behaviors for wine polyphenols in contact with oak wood. J Agric Food Chem 55:7021-7027

50. Coelho E, Domingues L, Teixeira JA, Oliveira JM, Tavares T (2019) Understanding wine sorption by oak wood: Modeling of wine uptake and characterization of volatile compounds retention. Food Res Int 116:249-257

51. Gonçalves FJ, Jordao AM (2009) Changes in antioxidant activity and the proanthocyanidin fraction of red wine aged in contact with portuguese (Quercus pyrenaica Willd.) and american (Quercus alba L.) oak wood chips. Ital J Food Sci 21:51-64

52. Vrhovsek U, Mattivi F, Waterhouse AL (2001) Analysis of red wine phenolics: comparison of HPLC and spectrophotometric methods. Vitis 40:87-91

53. De Coninck G, Jordão AM, Ricardo-da-Silva JM, Laureano O (2006) Evolution of phenolic composition and sensory properties in red wine aged in contact with Portuguese and French oak wood chips. OENO One 40:25-34

54. Gambuti A, Han G, Peterson AL, Waterhouse AL (2015) Sulfur dioxide and glutathione alter the outcome of microoxygenation. Am J Enol Viticult. https://doi.org/10.5344/ajev.2015.15005

55. Gambuti A, Siani T, Picariello L, Rinaldi A, Lisanti MT, Ugliano M, Dieval JB, Moio L (2017) Oxygen exposure of tannins-rich red wines during bottle aging. Influence on phenolics and color, astringency markers and sensory attributes. Eur Food Sci Technol 243:669-680

56. Barrera-García VD, Gougeon RD, Di Majo D, De Aguirre C, Voilley A, Chassagne D (2007) Different sorption behaviors for wine polyphenols in contact with oak wood. J Agr Food Chem 55:7021-7027

57. Oberholster A, Elmendorf BL, Lerno LA, King ES, Heymann H, Brenneman CE, Boulton RB (2015) Barrel maturation, oak alternatives and micro-oxygenation: Influence on red wine aging and quality. Food Chem 173:1250-1258

58. Canas S, Leandro MC, Spranger MI, Belchior AP (1999) Low molecular weight organic compounds of chestnut wood (Castanea sativa L.) and corresponding aged brandies. J Agr Food Chem 47:5023-5030

59. Cerezo AB, Tesfaye W, Torija MJ, Mateo E, García-Parrilla MC, Troncoso AM (2008) The phenolic composition of red wine vinegar produced in barrels made from different woods. Food Chem 109:606-615

60. Cano-López M, Bautista-Ortín AB, Pardo-Mínguez F, LópezRoca JM, Gómez-Plaza E (2008) Sensory descriptive analysis of a red wine aged with oak chips in stainless steel tanks or used barrels: effect of the contact time and size of the oak chips. J Food Qual 31:645-660

61. Kozlovic G, Jeromel A, Maslov L, Pollnitz A, Orlić S (2010) Use of acacia barrique barrels-influence on the quality of Malvazija from Istria wines. Food Chem 120:698-702

62. Atanasova B, Thomas-Danguin T, Langlois D, Nicklaus S, Etievant P (2004) Perceptual interactions between fruity and woody notes of wine. Flavour Frag J 19:476-482

63. Atanasova B, Thomas-Danguin T, Langlois D, Nicklaus S, Chabanet C, Etievant P (2005) Perception of wine fruity and woody notes: influence of peri-threshold odorants. Food Qual Pref 16:504-510

64. Ferreira V, Sáenz-Navajas MP, Campo E, Herrero P, de la Fuente A, Fernández-Zurbano P (2016) Sensory interactions between six common aroma vectors explain four main red wine aroma nuances. Food Chem 199:447-456

65. Ramirez Ramirez G, Lubbers S, Charpentier C, Feuillat M, Voilley A, Chassagne D (2001) Aroma compound sorption by oak wood in a model wine. J Agr Food Chem 49:3893-3897

66. Ramirez-Ramirez G, Chassagne D, Feuillat M, Voilley A, Charpentier C (2004) Effect of wine constituents on aroma compound sorption by oak wood in a model system. Am J Enol Viticult $55: 22-26$

Publisher's Note Springer Nature remains neutral with regard to jurisdictional claims in published maps and institutional affiliations. 